\title{
Seminars on advance directives for adult outpatients increased completion rates
}

\author{
Landry FJ, Kroenke K, Lucas C, et al. Increasing the use of advance directives in medical outpatients.J Gen Intern Med 1997 \\ Jul;12:412-5.
}

\section{Objective}

To determine whether attendance at an educational seminar compared with receipt of postal information will increase the completion of advance directives by medical outpatients.

\section{Design}

Randomised controlled trial.

\section{Setting}

An internal medicine clinic in a military teaching hospital in Washington, DC, USA.

\section{Patients}

187 patients (mean age 62 y, 55\% women, $67 \%$ white) who did not have a written living will (advance directive) and requested information via a questionnaire filled out during a clinic visit. Exclusion criterion was inability to complete the questionnaire. Follow up was $91 \%$ at 1 month.

\section{Intervention}

95 patients were allocated to a standardised 60 minute seminar with 20 patients in each group. The seminar included a 10 minute didactic presentation on advance directives, durable power of attorney for health care, and organ donation; a 15 minute videotape provided by the New York Society for the Right to Die describing the formulation of advance directives; a 30 minute interactive discussion with a question and answer period; distribution of an information pamphlet; and distribution and discussion of an advance directive form. 92 patients were allocated to a control group and received the advanced directive form and an information pamphlet by post.

\section{Main outcome measures}

Self reported completion of the advance directive at 1 month. Secondary outcomes were reports of discussions of advance directives with families, friends, and physicians; establishment of written advance directives; and attitudes regarding the acceptability of the intervention.

\section{Main results}

65 patients $(68 \%)$ attended the seminars. At 1 month, more patients in the seminar group reported completing advance directives $(38 \% v 24 \%, \mathrm{p}=0.04)$ and having discussions on advance planning $(73 \% \cup 57 \%, \mathrm{p}=0.02)$ than in the control group. $92 \%$ of patients in the seminar group believed that the information they received about advance directives was beneficial as did $77 \%$ of patients in the control group $(p=0.02)$. A $30 \%$ random sample of patients who completed the advance directives showed that predictors for completion were white race (odds ratio [OR] 6.9, 95\% CI 5.8 to 8.0), attendance at the seminar (OR 4.1, CI 3.3 to 4.9), and marital status (OR 2.5, CI 1.6 to 3.4).

\section{Conclusion}

A 60 minute group seminar and written material were more effective than postal information alone for increasing completion of advance directives by adult outpatients.

Source of funding: Walter Reed Army Medical Center.

For article reprint:Dr F J Landry, University of Vermont, Fletcher Allen Health Care, 310 Pine Street, Burlington, VT 05401, USA. Fax +1 8028636639.

\section{Commentary}

Advance directives are written documents completed by individuals and their families to specify how they would like health care delivered should they not be able to speak for themselves. Consumer interest, legal requirements, and popular press information on advance directives have each created pressures for nurses and physicians to respond to patient requests on these topics. Two other research teams have recently addressed these pressures. The study reported by Landry et al is consistent with recommendations made by Haisfield $e t$ al about patients and providers in an oncology setting. ${ }^{1}$ Patterson et al studied community based nurses and used one on one education opportunities with elders who had chronic illness and were living at home. They reported that younger patients or patients with specific nurses were more likely to complete written advance directives. ${ }^{2}$
The reasons patients attended clinic and their stage of wellness were not given in the study by Landry et al and therefore their results for adult education success may not be generalisable to other populations who are experiencing the uncertainty or stress of illness. The 2 study groups, those who attended the 60 minute seminar and those who received written material alone, were demographically well matched. One critical element for completion of advance directives is follow up. The 1 month follow up rate of $91 \%$ is exemplary. The format of the study group session is clearly described for other nurse educators to replicate.

Nurses working in a variety of environments could use the components of this study to plan and implement effective group teaching about advance directives or organ donation. Such settings could include community wellness clinics, public meetings, oncology clinics, gerontology clinics, or medical clinics for chronic illness. As increasing numbers of individuals are admitted to long term facilities, members of the healthcare team may select to use the group format suggested here and follow up on an individual basis for selected patients and their proxies.

Beverley Jones, RN, MScN Clinical Nurse Specialist Kingston Psychiatric Hospital Kingston, Ontario, Canada

1 Haisfield ME, McGuire DB, Krumm S, et al. Patients' and healthcare providers' opinions regarding advance directives. Oncol Nurs Forum 1994;21:1179-87.

2 Patterson C, Molloy DW, Guyatt GH, et al. Systematic implementation of an advance health care directive in the community. Can J Nurs Admin 1997;10:96-108. 